\title{
Células mononucleares autólogas de medula óssea na regeneração do nervo tibial de coelhos submetidos à neurectomia: aspectos morfofuncionais
}

\section{Autologous mononuclear bone marrow cells in the regeneration of tibial nerve of rabbits submitted to neurectomy: morphofunctional aspects}

\author{
Camila França de Paula Orlando-Goulart ${ }^{1 *}$; Daniel Silva Goulart²; \\ Leandro Guimarães Franco ${ }^{3}$; Benito Juarez Nunes Alves Oliveira ${ }^{4}$; \\ Danilo Rezende Silva ${ }^{5}$; Luiz Augusto Souza ${ }^{6}$; Luiz Antônio Franco Silva \\ Adilson Donizeti Damasceno ${ }^{8}$
}

\section{Resumo}

A recuperação funcional de nervos periféricos após lesão é o principal objetivo da intervenção terapêutica. Por isso o objetivo deste estudo foi avaliar clinicamente a recuperação funcional de coelhos após neurectomia e tratamento com células mononucleares de medula óssea associada à técnica de tubulização. Foram utilizados para isto, 24 coelhos da raça Nova Zelândia, alocados em dois grupos com 12 animais cada, denominados grupo célula mononuclear (GCM) e grupo solução salina (GSS). Os coelhos foram submetidos à secção do nervo tibial direito e reparação por meio da técnica de tubulização utilizando tubo oco de silicone, para então, receberem no interior do tubo, $0,1 \mathrm{~mL}$ de suspensão de células mononucleares autólogas de medula óssea ( 2 x 106 células) no GCM e solução salina no GSS, para comparação da evolução da recuperação funcional dos membros operados. Foram realizadas avaliações da marcha e planimetria da pegada do membro pélvico impressa em papel a partir de tinta à base d'água aplicada à área plantar, antes (M0) e após o $7^{\circ}(\mathrm{M} 7), 15^{\circ}(\mathrm{M} 15), 30^{\circ}(\mathrm{M} 30), 45^{\circ}(\mathrm{M} 45)$ e $60^{\circ}(\mathrm{M} 60)$ dias do procedimento cirúrgico. Os resultados mostraram que não houve a recuperação funcional do nervo tibial em ambos os grupos, sem diferença entre eles nos diferentes momentos e entre os momentos dentre dos grupos, exceto quando comparado com M0.

Palavras-chave: Implante autólogo, regeneração tecidual, terapia celular

\footnotetext{
${ }^{1}$ Discente de Doutorado em Ciência Animal, Escola de Veterinária e Zootecnia, Universidade Federal de Goiás, UFG, Goiânia, GO. Bolsista CNPq. E-mail: camilafrancavet@gmail.com

${ }^{2}$ Discente de Doutorado em Ciência Animal, Escola de Veterinária e Zootecnia, UFG, Goiânia, GO. Bolsista Capes. E-mail: dsgvet@hotmail.com

${ }^{3}$ Prof. Dr. da Universidade Estadual de Santa Cruz, Ilheus, Bahia. E-mail: lg.franco@yahoo.com.br

${ }^{4}$ Médico Veterinário Dr. em Ciência Animal, Escola de Veterinária e Zootecnia, UFG, Goiânia, GO. E-mail:benito@ortoneurovet. com

${ }^{5}$ Discente de Mestrado em Ciência Animal, Escola de Veterinária e Zootecnia, UFG, Goiânia, GO. E-mail: drs-patovet@hotmail. com

${ }^{6}$ Prof. Dr. da Escola de Veterinária e Zootecnia, UFG, Goiânia, GO. E-mail: souza_vet@yahoo.com.br

${ }^{7}$ Prof. Associado II da Escola de Veterinária e Zootecnia, UFG, Goiânia, GO. E-mail: prof_ufg.dmv@hotmail.com

${ }^{8}$ Prof. Dr. da Escola de Veterinária e Zootecnia, UFG, Goiânia, GO. E-mail: addamasceno@vet.ufg.br

* Autor para correspondência
} 


\begin{abstract}
The functional recovery after peripheral nerve injury is the main goal of therapeutic intervention. Therefore the aim of this study was to clinically evaluate functional recovery in rabbits after neurectomy and treatment with bone marrow mononuclear cells associated with the tubulization technique. For this, 24 New Zealand rabbits, were used. They were divided into two groups with 12 animals each, mononuclear cell group (MCG) and saline group (SSG). The rabbits underwent right tibial nerve section and repair by the tubulization technique using silicone hollow tube, which received $0.1 \mathrm{ml}$ of autologous mononuclear bone marrow cells $(2 \times 106$ cells $)$ in the MCG and of saline solution in the SSG, in order to compare the evolution of functional recovery of the operated limbs. Gait and planimetry were performed. Planimetry of the pelvic limb footprint printed on paper with water-based ink applied to the plantar area, before (M0) and after 7 (M7), 15 (M15), 30 (M30), 45 (M45) and 60 (M60) days after surgery. The results showed no functional recovery of the tibial nerve in both groups, without differences between them in different times and among times within groups, except when compared to M0.
\end{abstract}

Key words: Autologous implantation, cellular therapy, tissue regeneration

\section{Introdução}

As lesões de nervos periféricos geralmente levam a grande perda da função motora e sensorial. Devido às complexas exigências para uma regeneração axonal adequada, a recuperação funcional raramente ocorre. Os modelos experimentais são uma ferramenta útil para investigar os mecanismos relacionados à regeneração axonal, reinervação e para testar novas estratégias para permitir o restabelecimento da função nervosa (NAVARRO; UDINA, 2009).

A recuperação funcional é um dos principais objetivos da intervenção terapêutica em lesões de nervos periféricos (COSTA et al., 2009) e, para que ocorra satisfatoriamente, é necessário que haja adequada regeneração do nervo lesionado. Neste sentido, a utilização de células-tronco vem se tornando uma alternativa, pois estas células são fonte promissora de proliferação e diferenciação celular (NEIVA, 2005), sendo a medula óssea, o local mais acessível de sua obtenção por meio das células mononucleares (ZAGO; COVAS, 2004).

Para avaliar a contribuição que estas células trazem na recuperação tecidual e principalmente funcional de nervos periféricos a avaliação clínica é de fundamental importância. Trindade (2009) avaliou a marcha de coelhos submetidos à lesão do nervo femoral, adaptando os parâmetros de claudicação dos cães por não haver na literatura parâmetros para espécie em questão. Além disso, testes que avaliam o índice funcional de nervos periféricos também têm sido amplamente aplicados em ratos. DeMedinaceli, Freed e Wyatt (1982) desenvolveram um método avaliativo quantitativo, confiável e reprodutível, da condição funcional do nervo ciático de ratos, para a avaliação do grau de lesão e da recuperação, denominado de Índice Funcional do Ciático. Este método consiste em analisar as impressões das pegadas dos animais, contudo, não há descrição de sua validade na análise de pegadas de coelhos, uma espécie empregada também nos estudos de regeneração nervosa.

Assim exposto, este trabalho objetivou, por meio de um modelo experimental, verificar se a terapia celular com células mononucleares autólogas providas da medula óssea, em associação com a técnica de tubulização, possui efeitos na recuperação funcional do nervo tibial em coelhos da raça Nova Zelândia.

\section{Material e Métodos}

O presente estudo foi desenvolvido na Escola de Veterinária e Zootecnia (EVZ) da Universidade Federal de Goiás (UFG) no período de julho a outubro de 2010. Na pesquisa foram empregados 24 coelhos da raça Nova Zelândia, machos e fêmeas, 
saudáveis, pesando aproximadamente $3,0 \mathrm{~kg}$. Os animais foram mantidos em gaiolas individuais onde recebiam água ad libitum e ração segundo recomendação do fabricante (Ração do Sítio Coelhão ${ }^{\circledR}$ - Guabi Nutrição Animal, Anápolis - Go).

Os animais foram submetidos a um período de condicionamento de 40 dias para se acostumarem à manipulação e a caminhar por um corredor de madeira construído para avaliação clínica pósoperatória da locomoção. Os coelhos foram alocados em dois grupos com 12 animais cada, com a seguinte denominação, grupo célula mononucleares (GCM) e grupo solução salina (GSS). Os coelhos do GCM foram tratados com células mononucleares autólogas obtidas de medula óssea e os coelhos do GSS receberam solução salina (solução de cloreto de sódio a $0,9 \%$ ) na reparação do nervo tibial, conforme protocolo a seguir.

Para o procedimento de colheita e isolamento da fração mononuclear da medula óssea, os animais foram submetidos à anestesia injetável com uma associação de $1,0 \mathrm{mg} / \mathrm{kg}$ de sulfato de morfina (Dimorf ${ }^{\mathbb{B}}$, Cristália - Produtos Químicos Farmacêuticos Ltda, Itapira/SP), 1,0mg/kg de cloridrato de xilazina (Calmiun ${ }^{\circledR}$, Agener União, São Paulo/SP); 2,0mg/Kg de cloridrato de midazolan (Midazolan $^{\circledR}$, União Química, Jabaquara/SP) e $30 \mathrm{mg} / \mathrm{kg}$ de cloridrato de cetamina $\left(\right.$ Ketamina $^{\circledR}$, Agener União, São Paulo/SP), por via intramuscular. Após o decúbito lateral, procedeu-se a canulação da veia auricular lateral com cateter 24G. Durante todo o período de anestesia foi fornecido oxigênio, por máscara facial, com fluxo de $2 \mathrm{~L} / \mathrm{min}$. Em seguida realizou-se tricotomia na região do tubérculo umeral para a colheita de medula óssea.

Sequencialmente, com o animal em decúbito lateral, foi realizada flexão da articulação escápuloumeral e introdução de uma agulha hipodérmica 25X8G previamente heparinizada na região do tubérculo umeral. Com uma seringa de $10 \mathrm{ml}$ também previamente heparinizada colheu-se em média $5 \mathrm{ml}$ de medula óssea íntegra. Em seguida, o material foi encaminhado ao Laboratório do Departamento de Genética e Citogenética, do Instituto de Ciências Biológicas da UFG, para isolamento, determinação do rendimento e da viabilidade das células mononucleares segundo protocolo descrito por Oliveira (2009) e Souza (2009).

Os aspirados de medula óssea foram colocados individualmente em tubos estéreis de $15 \mathrm{~mL}$ tipo Falcon e adicionou-se solução salina tamponada de Dulbecco (DPBS). A solução formada foi adicionada lentamente sobre uma solução Ficoll-HypaquePlus (Histopaque 1077 - Sigma Aldrich, St. Louis, EUA) em outro tubo Falcon, para separação das células-tronco mononucleares. Essa nova solução foi centrifugada durante 30 minutos a $15^{\circ} \mathrm{C}$ para separação das células mononucleares, e as células foram colhidas com o auxílio de pipeta Pasteur e transferidas para um tubo estéril de $15 \mathrm{~mL}$.

Após esta etapa, adicionou-se à amostra $1,0 \mathrm{~mL}$ de tampão de lise de eritrócitos durante cinco minutos. Uma terceira lavagem foi realizada com a adição de $10 \mathrm{~mL}$ de DMEM (Dulbecco's Modified Eagle Medium) suplementado com 10\% de soro fetal bovino. Posteriormente desprezado, permanecendo aderido no fundo do tubo apenas o aglomerado celular. Adicionou-se ao sedimento celular a quantidade necessária do meio DMEM suplementado com $10 \%$ de soro fetal bovino, até que a amostra atingisse o volume total de $500 \mu \mathrm{l}$. Deste volume, uma alíquota de $10 \mu 1$ da suspensão foi adicionada a $10 \mu 1$ do corante azul de Tripan em um tubo de Eppendorf para contagem das células em câmara hemocitométrica de Neubauer. A viabilidade foi determinada por técnica de exclusão vital, ou seja, das células não coradas por azul de Tripan.

No intuito de padronizar a quantidade de células inoculadas no interior do tubo de silicone, foi obtido o fator de diluição de cada amostra por meio de cálculo demonstrado na Tabela 1 . Obteve-se um volume final de aproximadamente $0,1 \mathrm{ml}$ contendo $2 \times 10^{6}$ células mononucleares. Os volumes finais 
foram armazenados em seringas estéreis de $1,0 \mathrm{~mL}$, mantidas em refrigeração até o momento da aplicação nos procedimentos cirúrgicos.

Para o procedimento cirúrgico além do protocolo anestésico utilizado para a colheita de medula óssea, realizou-se anestesia epidural entre a última vértebra lombar e a primeira vértebra sacral, empregando uma associação de $5,0 \mathrm{mg} / \mathrm{kg}$ de cloridrato de lidocaína sem vasoconstritor a $2 \%$ (Anestésico $\mathrm{L}^{\circledR}$, Pearson, Eurofarma, São Paulo/SP) e $0,6 \mathrm{mg} / \mathrm{kg}$ de cloridrato de bupivacaína sem vasoconstritor a $0,5 \%$ (Neocaína ${ }^{\circledR}$, Cristália - Produtos Químicos Farmacêuticos Ltda, Itapira/SP) tomando o cuidado para não ultrapassar o volume de $0,25 \mathrm{~mL} / \mathrm{kg}$, como descrito rotineiramente para outras espécies domésticas (SKARDA; TRANQUILI, 2007).

Tabela 1. Equações matemáticas para a determinação do número de células, viabilidade celular e do fator de diluição para o processo de isolamento, contagem e viabilidade das células-tronco mononucleares.

\begin{tabular}{|c|c|}
\hline DESCRIÇÃ̃O & FÓRMULA \\
\hline $\begin{array}{l}\text { Cálculo do número de células por } \\
\text { mililitro (NC) }\end{array}$ & $\begin{array}{c}\mathbf{N C}=\mathbf{V} \mathbf{x} \mathbf{F N} \mathbf{x} \mathbf{F T} / \# \mathbf{Q} \\
\text { Onde: } \mathrm{V}=\text { número de células viáveis contadas; FN = fator da câmara de } \\
\text { Neubauer }\left(10^{4}\right) ; \mathrm{FT}=\text { fator de diluição do Azul de Tripan }(2) ; \# \mathrm{Q}=\text { número } \\
\text { de quadrantes da câmara utilizados para a contagem. }\end{array}$ \\
\hline $\begin{array}{l}\text { Cálculo da viabilidade celular } \\
\text { determinada em porcentagem (VC) }\end{array}$ & $\begin{array}{l}\mathbf{V C}=\mathbf{V} \times \mathbf{~ 1 0 0 / N T} \\
\text { Onde: } \mathrm{NT}=\text { número total de células (viáveis e não viáveis) }\end{array}$ \\
\hline $\begin{array}{l}\text { Determinação do fator de diluição } \\
\text { (FD) }\end{array}$ & $\begin{array}{c}\mathbf{F D}=\mathbf{Q T} / \mathbf{C T} \\
\text { Onde: } \mathrm{QT}=\text { quantidade de células viáveis presente em } 500 \mu 1 \text { do sedimento } \\
\text { celular; } \mathrm{CT}=\text { quantidade de células a serem transplantadas }\left(2 \times 10^{6}\right) . \\
\mathbf{V F}=\mathbf{V I} / \mathbf{F D} \\
\text { Onde: } \mathrm{VF}=\text { volume final; } \mathrm{VI}=\text { volume inicial do inoculado }(500 \mu \mathrm{l}) \\
\mathrm{FD}=\text { fator de diluição }\end{array}$ \\
\hline
\end{tabular}

Fonte: Adaptado de Oliveira (2009).

Posteriormente, com o animal posicionado em decúbito lateral direito, foi realizada tricotomia na face do membro (Figura 1A), antissepsia de pele com a aplicação sequencial de álcool, iodopovidona e álcool e, realizado o acesso cirúrgico pela face lateral do membro (Figura 1B). Após incisão na fáscia lata (Figura 1C) e afastamento dos ventres dos músculos vasto lateral e bíceps femoral, foi localizado o nervo ciático e suas ramificações. Com auxílio de instrumental microcirúrgico o nervo foi dissecado de seu leito, isolando a porção tibial (Figura 1D) identificada por se localizar mais cranialmente em relação ao nervo fibular. Por meio da secção aguda com lâmina de bisturi foi criado um defeito nervoso de $5 \mathrm{~mm}$ no terço médio de seu comprimento exposto pela ferida cirúrgica. Em seguida, as extremidades de um tubo oco de silicone
(Medicone $^{\circledR}$, Fibra cirúrgica, Cachoeririnha/RS) medindo $1,5 \mathrm{~mm}$ e 2,42 $\mathrm{mm}$ de diâmetro interno e externo, respectivamente, e $15 \mathrm{~mm}$ de comprimento, foram fixadas à camada epineural das extremidades dos cotos do nervo com fio monofilamentar de náilon, calibre 6-0 (Technofio ${ }^{\circledR}$ - Ace Ind. e Com., Goiânia/GO) em padrão interrompido simples (Figura 1E).

No espaço entre os cotos do nervo tibial delimitado pelo lúmen do tubo de silicone, foi injetada a fração de células mononucleares autólogas de medula óssea em um volume de $0,1 \mathrm{ml}$ no GCM (Figura 1F). Nos animais do grupo GSS foi injetado o mesmo volume de solução de cloreto de sódio a $0,9 \%$, conforme previamente descrito. No pós-operatório, foi administrado antibiótico a base de cefazolina sódica, $30 \mathrm{mg} / \mathrm{kg}$, por via IM, 
de 12/12 horas durante sete dias. Para analgesia, foi utilizado o cloridrato de tramadol (Cloridrato de tramadol ${ }^{\circledR}$, União Química Farmacêutica Nacional S/A, Pouso Alegre/MG) $2,0 \mathrm{mg} / \mathrm{kg}$, via subcutânea, de $12 \mathrm{em} 12$ horas, durante os três primeiros dias.
Os curativos da ferida cirúrgica foram realizados uma vez ao dia, com gazes umedecidas em solução de cloreto de sódio à $0,9 \%$, por 10 dias. Durante o período pós-operatório os coelhos foram mantidos com colar elizabetano.

Figura 1. Etapas do procedimento cirúrgico de lesão experimental e reparação pela técnica de tubulização, do nervo tibial em coelho. A) tricotomia ampla no membro pélvico direito para o acesso cirúrgico; B) incisão de pele e subcutâneo; C) incisão da fascia lata; D) isolamento da porção tibial do nervo ciático; E) introdução do coto nervoso no interior do tubo de silicone; F) aplicação das células mononucleares ou solução fisiológica no interior do tubo de silicone.

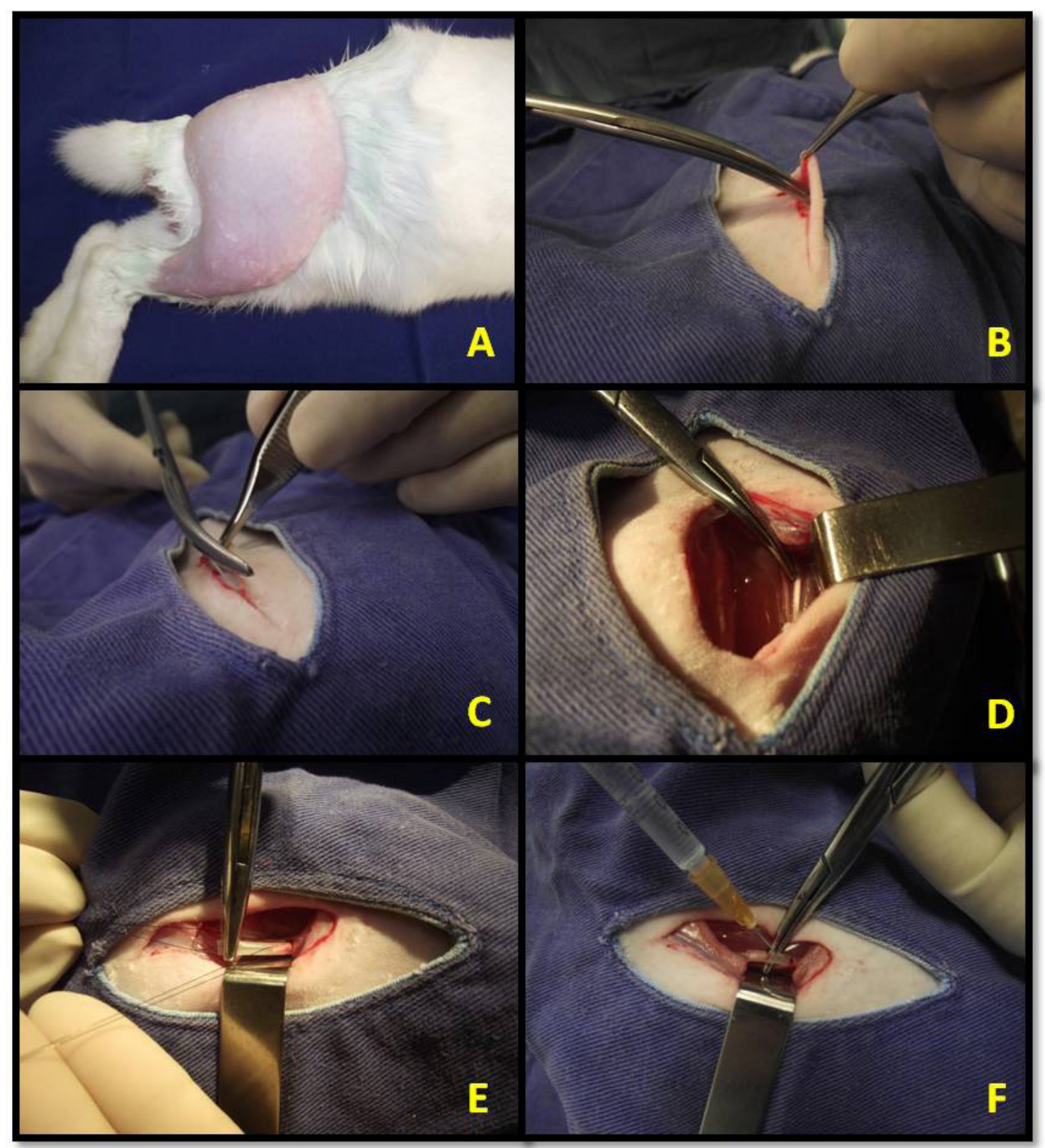

Fonte: Elaboração dos autores. 
Para a avaliação clínica da locomoção os coelhos foram colocados em um corredor de $2 \mathrm{~m}$ de comprimento e $0,25 \mathrm{~m}$ de largura e a imagem foi vídeo-documentada por meio de uma câmera filmadora digital para posterior avaliação da marcha (Figura 2A). Foram analisadas seis passadas por animal e estabeleceu-se um escore de frequência de passos com déficit de flexão, que foi assim constituído: grau 0 - passos sem déficit de flexão; grau 1 - um a dois passos com déficit; grau 2 - três a quatro passos com déficit; e grau 3 - cinco a seis passos com déficit. As avaliações da marcha e a planimetria foram realizadas antes do procedimento cirúrgico (M0) e aos sete (M7), 15(M15), 30(M30), 45(M45) e 60(M60) dias após o procedimento cirúrgico.

Figura 2. Avaliação da locomoção e das pegadas de coelhos após indução de lesão do nervo tibial e reparação por meio da técnica de tubulização e tratados (Grupo Célula Mononuclear - GCM) ou não (Grupo Solução Salina - GSS) com células mononucleares de medula óssea. A) corredor onde foram capturadas as imagens de vídeo para posterior análise da marcha; B) teste de avaliação da área de impressão de apoio dos membros pélvicos; C) e D) impressões das pegadas dos coelhos. Nota-se que a impressão da pegada do membro operado do GSS (seta da figura C) foi maior que no membro operado do GCM (seta da figura D) após sete dias do procedimento cirúrgico realizado no Hospital Veterinário da Escola de Veterinária e Zootecnia da UFG de julho-outubro de 2010.

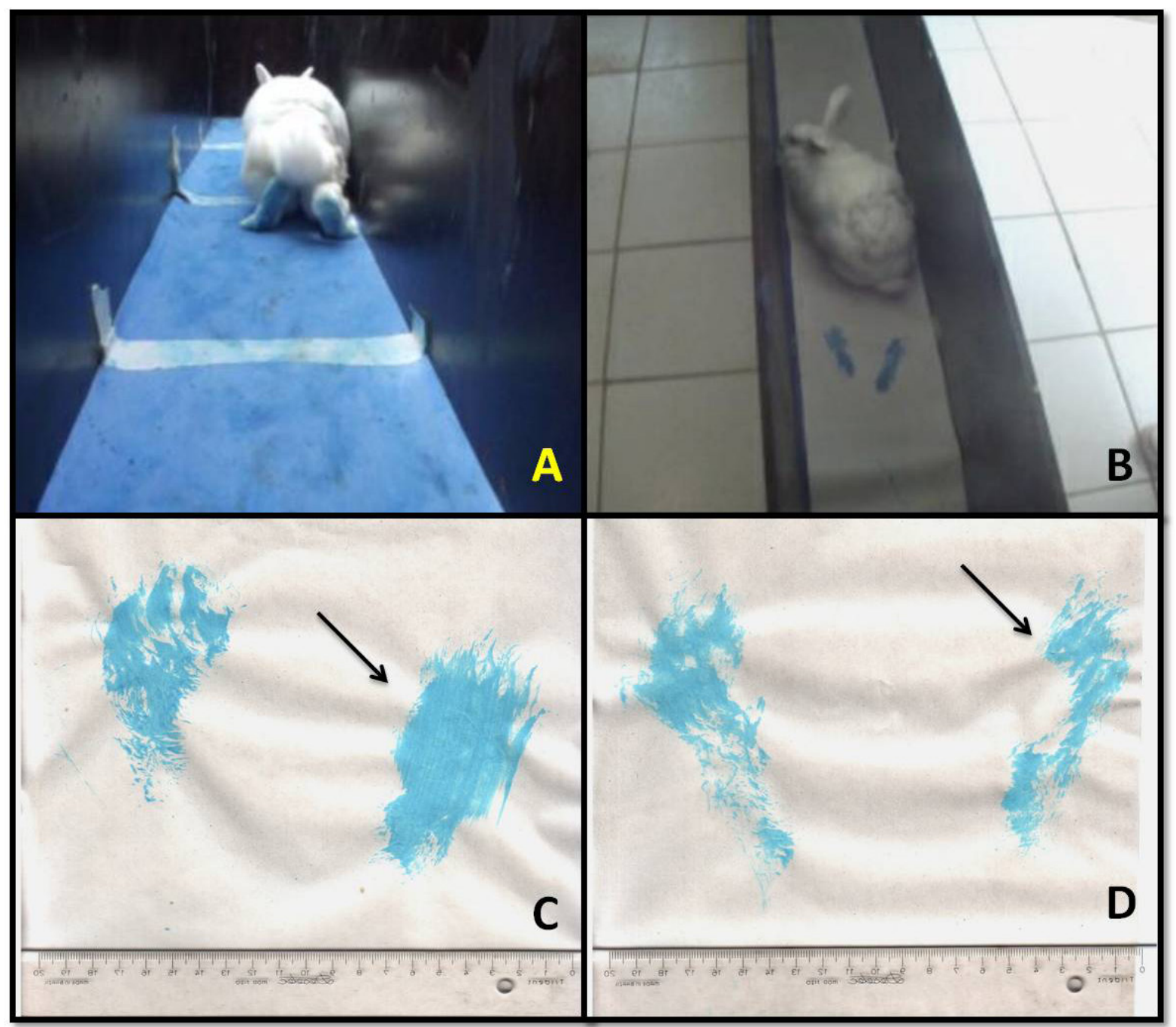

Fonte: Elaboração dos autores. 
Posteriormente à avaliação da marcha foi realizado a planimetria tingindo a região plantar dos membros pélvicos dos coelhos com tinta a base d'água e os coelhos foram colocados para caminhar pelo corredor utilizado para avaliação clínica. Utilizou-se papel branco com o objetivo de registrar a pegada de cada membro delimitada pela tinta nele impregnada (Figura 2B). As impressões dos pontos de apoio do membro operado e do membro contralateral foram escaneadas e analisadas no programa Image $J$ (National Institutes of Health, United States of America, http://rsbweb.nih.gov/ij/ download.html).

Para a análise estatística foi utilizado o teste de Mann-Whitney para a avaliação da marcha e Análise de Variância em parcelas subdivididas para avaliação das pegadas. Os resultados foram considerados significativos quando $\mathrm{p}<0,05$.

\section{Resultados}

A colheita de medula óssea através do tubérculo umeral não causou nenhum tipo de alteração locomotora nos animais ou outros tipos de alterações. Na colheita foi possível a obtenção de quantidade suficiente de medula óssea íntegra e após o processo de separação, contagem e determinação da viabilidade das células mononucleares se obtiveram uma média de $13,45 \times 10^{6}$ células por animal com viabilidade média de $95,37 \%$.

Em relação ao procedimento cirúrgico, não houve dificuldade no acesso ao nervo tibial, nem na execução da técnica de tubulização. Além disso, no pós-operatório houve completa cicatrização da ferida cirúrgica em todos os animais sem alterações como secreção, hiperemia ou deiscência da ferida. No entanto, durante o período de avaliação foi observado no membro operado de seis animais de cada grupo uma pododermatite ulcerativa na região da articulação tibiotársica.

As avaliações clínicas da marcha foram realizadas sempre pelo mesmo observador em todos os momentos na forma de avaliação as "cegas", ou seja, o observador não tinha a informação que qual grupo cada animal pertencia. Os valores dos escores dos animais estão descritos na Tabela 2. No M0 nenhuma alteração de locomoção foi verificada em ambos os grupos. No M7 observouse no GSS escore três em 91,66\% dos animais e escore dois em $8,34 \%$. No GCM todos os animais (100\%) obtiveram escore três em M7. No M15 em ambos os grupos $100 \%$ dos animais obtiveram escore três. No M30 do GSS um animal apresentou escore dois $(8,34 \%)$ e os outros animais obtiveram escore três $(91,66 \%)$, já no GCM todos os animais obtiveram escore três exceto o animal 1025 que se recusou a andar. No M45 o GSS apresentou dois animais com escore dois $(16,6 \%)$ e os outros com escore três $(83,4 \%)$ sendo que dois animais também se recusaram a andar. Já no GCM apenas um animal $(8,34 \%)$ obteve escore dois e os demais escore três. Por fim, no M60 encontrou-se escore dois em um animal $(8,34 \%)$ e escore três em nove animais $(91,66 \%)$ no GSS sendo que um animal novamente se recusou a andar. No GCM todos os animais (100\%) obtiveram escore três. Dos 12 animais do GSS apenas três deles se recusaram a andar em apenas um momento cada, e destes três animais apenas um tinha pododermatite de grau leve. Já no grupo GCM apenas um animal se recusou a andar em apenas um momento e este não possuía lesão de pododermatite. Os animais que apresentaram pododermatite não foram tratados para não influenciar no resultado da avaliação clínica.

O déficit de flexão no membro direito encontrado na avaliação da marcha foi sutil a ponto de precisar reduzir a velocidade de execução do filme para que fosse observada tal alteração. Já nos animais que possuíam a pododermatite essa alteração foi mais acentuada. Na análise estatística observou-se diferença significativa $(\mathrm{p}<0,05)$ somente entre $\mathrm{o}$ M0 e o M7, M15, M30, M45 e M60, mas não entre os grupos. 
Tabela 2. Escores da marcha de coelhos submetidos à lesão no nervo tibial com reparação por meio da técnica de tubulização tratados com células mononucleares de medula óssea (GCM) ou com solução de Cloreto de sódio a $0,9 \%$ (GSS), antes do procedimento cirúrgico (M0) e aos sete (M7), 15(M15), 30(M30), 45(M45) e 60(M60) dias após o procedimento cirúrgico realizado no Hospital Veterinário da Escola de Veterinária e Zootecnica da UFG de julhooutubro de 2010.

\begin{tabular}{|c|c|c|c|c|c|c|c|}
\hline Grupos & Animal & M0 & M7 & M15 & M30 & M45 & M60 \\
\hline \multirow{12}{*}{ Solução salina } & 1002 & $0^{\mathrm{a}}$ & $3^{b}$ & $3^{b}$ & $3^{b}$ & $3^{b}$ & $3^{b}$ \\
\hline & 1003 & $0^{\text {a }}$ & $3^{b}$ & $3^{b}$ & $3^{b}$ & $3^{b}$ & $3^{b}$ \\
\hline & 1004 & $0^{\text {a }}$ & $2^{b}$ & $3^{b}$ & $3^{b}$ & $3^{b}$ & $3^{b}$ \\
\hline & 1005 & $0^{\text {a }}$ & $3^{b}$ & $3^{b}$ & $3^{\mathrm{b}}$ & $2^{b}$ & $3^{b}$ \\
\hline & 1006 & $0^{\text {a }}$ & $3^{b}$ & $3^{b}$ & $2^{b}$ & $2^{b}$ & - \\
\hline & 1007 & $0^{\text {a }}$ & $3^{b}$ & $3^{b}$ & $3^{b}$ & $3^{b}$ & $3^{b}$ \\
\hline & 1008 & $0^{\text {a }}$ & $3^{b}$ & $3^{b}$ & $3^{b}$ & - & $3^{b}$ \\
\hline & 1009 & $0^{\text {a }}$ & $3^{b}$ & $3^{b}$ & $3^{b}$ & - & $2^{b}$ \\
\hline & 1010 & $0^{\text {a }}$ & $3^{b}$ & $3^{b}$ & $3^{b}$ & $3^{b}$ & $3^{b}$ \\
\hline & 1012 & $0^{\text {a }}$ & $3^{b}$ & $3^{b}$ & $3^{b}$ & $3^{b}$ & $3^{b}$ \\
\hline & 1013 & $0^{\text {a }}$ & $3^{b}$ & $3^{b}$ & $3^{b}$ & $3^{b}$ & $3^{b}$ \\
\hline & 1026 & $0^{\text {a }}$ & $3^{b}$ & $3^{b}$ & $3^{b}$ & $3^{b}$ & $3^{b}$ \\
\hline \multirow{12}{*}{$\begin{array}{c}\text { Células } \\
\text { Mononucleares }\end{array}$} & 1014 & $0^{\text {a }}$ & $3^{b}$ & $3^{b}$ & $3^{b}$ & $3^{b}$ & $3^{b}$ \\
\hline & 1015 & $0^{\text {a }}$ & $3^{b}$ & $3^{\mathrm{b}}$ & $3^{b}$ & $3^{b}$ & $3^{b}$ \\
\hline & 1016 & $0^{\text {a }}$ & $3^{b}$ & $3^{b}$ & $3^{b}$ & $3^{b}$ & $3^{b}$ \\
\hline & 1017 & $0^{\text {a }}$ & $3^{b}$ & $3^{b}$ & $3^{\mathrm{b}}$ & $3^{b}$ & $3^{b}$ \\
\hline & 1018 & $0^{\mathrm{a}}$ & $3^{b}$ & $3^{b}$ & $3^{b}$ & $3^{b}$ & $3^{b}$ \\
\hline & 1019 & $0^{\mathrm{a}}$ & $3^{b}$ & $3^{b}$ & $3^{b}$ & $3^{b}$ & $3^{b}$ \\
\hline & 1020 & $0^{\text {a }}$ & $3^{b}$ & $3^{b}$ & $3^{b}$ & $3^{b}$ & $3^{b}$ \\
\hline & 1021 & $0^{\text {a }}$ & $3^{b}$ & $3^{b}$ & $3^{b}$ & $3^{b}$ & $3^{b}$ \\
\hline & 1022 & $0^{\mathrm{a}}$ & $3^{b}$ & $3^{b}$ & $3^{b}$ & $3^{b}$ & $3^{b}$ \\
\hline & 1023 & $0^{\text {a }}$ & $3^{b}$ & $3^{b}$ & $3^{b}$ & $3^{b}$ & $3^{b}$ \\
\hline & 1024 & $0^{\text {a }}$ & $3^{b}$ & $3^{b}$ & $3^{b}$ & $2^{b}$ & $3^{b}$ \\
\hline & 1025 & $0^{\mathrm{a}}$ & $3^{b}$ & - & $3^{b}$ & $3^{b}$ & $3^{b}$ \\
\hline
\end{tabular}

0 - passos sem déficit de flexão; 2 - três a quatro passos com déficit de flexão; 3 - cinco a seis passos com déficit de flexão. Letras diferentes na mesma linha diferem significativamente pelo teste de Mann-Whitney para $\mathrm{p}<0,05$.

Fonte: Elaboração dos autores.

Na avaliação da área de impressão de apoio dos membros sobre o papel, obtiveram-se os valores médios que estão apresentados na Tabela 3. No GCM o membro operado apresentou uma média da área de apoio de $14,70 \mathrm{~cm}^{2}$ e um desvio padrão de 1,21 enquanto que no GSS observou-se uma área de
$15,75 \mathrm{~cm}^{2}$ e um desvio padrão de 1,81 . Na análise estatística não foi observada diferença significativa entre os grupos nos diferentes momentos, nem dentro do grupo entre os momentos. Também não foram observadas diferenças significativas entre o membro operado e o membro normal dos coelhos. 
Tabela 3. Valores, média e desvio padrão (DP) $\mathrm{em}^{2} \mathrm{~cm}^{2} \mathrm{da}$ área das impressões das pegadas de coelhos após lesão no nervo tibial submetidos a técnica de tubulização tratados (GCM) ou não (GSS) com células mononucleares autólogas de medula óssea em estudo realizado na Escola de Veterinária e Zootecnia da UFG de julho-outubro de 2010.

\begin{tabular}{ccccc}
\hline \multirow{2}{*}{ Momentos } & \multicolumn{2}{c}{ GCM } & \multicolumn{2}{c}{ GSS } \\
\cline { 2 - 5 } M0 & ESQ & DIR & ESQ & DIR \\
\cline { 2 - 5 } & $13,76^{\mathrm{a}}$ & $14,3^{\mathrm{a}}$ & $14,7^{\mathrm{a}}$ & $15,26^{\mathrm{a}}$ \\
M7 & $13,16^{\mathrm{a}}$ & $13,03^{\mathrm{a}}$ & $14,36^{\mathrm{a}}$ & $12,44^{\mathrm{a}}$ \\
M15 & $14,48^{\mathrm{a}}$ & $16,12^{\mathrm{a}}$ & $15,56^{\mathrm{a}}$ & $17,68^{\mathrm{a}}$ \\
M30 & $15,15^{\mathrm{a}}$ & $16,13^{\mathrm{a}}$ & $15,32^{\mathrm{a}}$ & $16,26^{\mathrm{a}}$ \\
M45 & $14,95^{\mathrm{a}}$ & $14,6^{\mathrm{a}}$ & $18,21^{\mathrm{a}}$ & $16,86^{\mathrm{a}}$ \\
M60 & $14,28^{\mathrm{a}}$ & $14,07^{\mathrm{a}}$ & $17,69^{\mathrm{a}}$ & $15,85^{\mathrm{a}}$ \\
\hline MÉDIA & 14,29667 & 14,70833 & 15,97333 & 15,725 \\
DP & 0,744168 & 1,217923 & 1,59822 & 1,812156 \\
\hline
\end{tabular}

Letras diferentes diferem significativamente pelo teste de Análise de Variância em parcelas subdivididas $\mathrm{p}<0,05$.

Fonte: Elaboração dos autores.

\section{Discussão}

A escolha do coelho como modelo experimental permitiu reduzir complicações referentes à manipulação e os custos com a manutenção dos animais. Além disso, a facilidade do acesso cirúrgico e a espessura do nervo tibial facilitaram a utilização de fios de sutura e do tubo de silicone de maior calibre em comparação aos utilizados em ratos. Colomé et al. (2008) e Trindade (2009) relataram em seus estudos as mesmas observações quanto ao custo do experimento e facilidade de manipulação desta espécie animal.

Em relação à colheita da medula óssea, não foram observadas intercorrências como alterações de locomoção no membro torácico, hematomas na região da punção e infecções ósseas após o procedimento. Eurides et al. (2010), Oliveira (2009), Souza (2009) e Im et al. (2001) também não observaram qualquer tipo de alteração no local da punção. Além disso, neste trabalho, a técnica de punção no tubérculo umeral, pela flexão da articulação escápulo-umeral, permitiu a exata localização do ponto de punção, facilitando a introdução da agulha na cortical óssea como também conseguido por Eurides et al. (2010).

O rendimento médio das células mononucleares deste estudo foi superior ao de outros trabalhos demonstrando que o tubérculo umeral pode ser o local mais adequado para a obtenção de aspirados de medula óssea em coelhos, pois permitiu obter quantidade superior de células quando comparados a outros locais. Yanai et al. (2005) obtiveram uma média de $5 \times 10^{6}$ células $/ \mathrm{ml}$ enquanto que $\mathrm{Im}$ et al. (2001) obtiveram somente $3,4 \times 10^{6}$ células/ $\mathrm{ml}$ isoladas da medula óssea do fêmur e da tíbia de coelhos, respectivamente, confirmando a superioridade do rendimento das células deste estudo. A quantidade de células inoculadas foi de $2 \times 10^{6}$ por se tratar de uma quantidade suficiente para promover reparação tecidual e melhoria dos processos regenerativos conforme descrito por Suter et al. (2004).

A pododermatite ulcerativa observada durante o experimento pode ter ocorrido por excesso de pressão aplicada sobre o local acometido. Em condições normais, sabe-se que o coelho, em repouso, sustenta grande parte de seu peso sobre a região do calcâneo, tarso e metatarso (HARCOURT-BROWN, 2002). Desse modo, o excesso de fricção da região à grade da gaiola em decorrência do comprometimento motor do nervo tibial, junto com a perda da função sensitiva nessa região (GUTMANN; GUTMANN, 1942), podem ter favorecido o aparecimento e a evolução das lesões. As lesões associadas aos membros operados não se resumiram apenas à derme. Em muitos animais o processo inflamatório se estendeu até a articulação tíbiotársicametatársica, o que causava conseqüentemente dor à locomoção. Segundo Harcourt-Brown (2002), coelhos com artrite tendem a se manter imóveis ou poupar o membro lesionado, o que poderia explicar a observação de alterações mais acentuadas de marcha nesses animais. No entanto, neste estudo, a dor à locomoção não foi o fator determinante para a recusa de alguns animais a andar.

A metodologia de avaliação clínica da marcha 
foi baseada nos estudos de Beloozerova, Sirota e Swadlow (2003) que utilizaram uma caixa de 2,5m de comprimento e $50 \mathrm{~cm}$ da largura para observar a locomoção de coelhos e, consequentemente, analisar a atividade de seus neurônios motores. No entanto, a lesão no nervo tibial não causou alterações consistentes de locomoção como foi observado também por Trindade (2009). Tal fato explica a dificuldade encontrada neste estudo para a avaliação da marcha dos coelhos. Mesmo assim, apesar de sutil, encontrou-se um déficit de flexão que provavelmente se deve ao fato do nervo tibial inervar músculos flexores, essenciais para a adequada movimentação da região plantar do coelho para realizar saltitamentos, o que define o seu padrão típico de locomoção conforme Trindade (2009).

A diferença significativa entre o $\mathrm{M} 0$ e os demais momentos na avaliação da marcha, já era um resultado esperado, uma vez que no M0, os animais ainda não haviam sido submetidos à lesão no nervo tibial e a locomoção desenvolviase normalmente. Já do M7 até o M60, a ausência de diferença significativa permitiu inferir que não houve evolução do processo de reparação nervosa a ponto de restabelecer a função motora e, portanto, o padrão de locomoção característico da espécie não foi observado. Dourado (2002) e Evans (2000) afirmaram que apesar dos considerados avanços tecnológicos na reparação de nervos periféricos, a reabilitação de funções sensoriais e motoras continua sendo um desafio para os pesquisadores e que, mesmo havendo regeneração tecidual, o retorno às funções do nervo lesado é raramente alcançado.

A utilização da planimetria, mesmo não havendo descrição na literatura da aplicação deste teste em coelhos, justificou-se pelo fato de ser um animal que se movimenta em saltos, e o peso concentrar-se nos membros pélvicos no momento da locomoção, deixando um registro marcante no papel sobre o solo (Figura 2C e D) conforme Harcourt-Brown (2002). No entanto, o peso do coelho, os pêlos, a quantidade de tinta na pata e a diluição da tinta em água podem interferir no resultado. Assim, caso novos estudos consigam padronizar estas variáveis, a planimetria pode se tornar uma importante ferramenta para a avaliação da evolução clínica de coelhos com lesão no nervo tibial.

\section{Conclusão}

Nas condições em que foi conduzido este experimento, os coelhos que foram submetidos à neurectomia do nervo tibial e tratados com célulastronco autólogas da medula óssea não apresentaram melhores resultados clínicos quanto à recuperação funcional motora em comparação àqueles tratados com solução salina. Além disso, a planimetria mostrou-se ser um teste inviável para este tipo de avaliação em coelhos.

\section{Agradecimentos}

A Escola de Veterinária e Zootecnia da Universidade Federal de Goiás e ao programa de Pós-graduação em Ciência Animal. Ao Conselho Nacional de Desenvolvimento Científico (CNPq) pela concessão da bolsa e a Fundação de Amparo à Pesquisa do Estado de Goiás (FAPEG) pelo financiamento do estudo. A empresa GUABI pelo fornecimento da alimentação para os animais durante todo o período experimental.

O presente estudo foi desenvolvido após aprovação pelo Comitê de Ética em Pesquisa da UFG, protocolo ${ }^{\circ} 10 / 2009$ e foi realizado de acordo com as normas técnicas de biossegurança e ética.

\section{Referências}

BELOOZEROVA, I.; SIROTA, M. G.; SWADLOW, H. A. Activity of Different Classes of Neurons of the Motor Cortex during Locomotion. The Journal of Neuroscience, Baltimore, v. 23, n. 3, p. 1087-1097, 2003.

COLOMÉ, L. M.; GOMES, C.; CROSIGNAN, N.; PAZ, A. H.; LUGO, A. A.; GUIMARÃES, K. M.; FOERSTROW, L. P.; TESSARI, J. P.; COLOMÉ, L. M.; GRAÇA, D. L.; MEURER, L.; PASSOS, E. P.; PIPPI, 
N. L.; CONTESINI, E. A.; LIMA, E. O. C. Utilização de células-tronco autólogas de medula óssea na regeneração do nervo tibial de coelhos mediante técnica de tubulização com prótese de silicone. Ciência Rural, Santa Maria, v. 38, n. 9, p. 2529-2534, 2008.

COSTA, L. M.; SIMÕES, M. J.; MAURICIO, A. C.; VAREJÃO, A. S. P. Methods and protocols in peripheral nerve regeneration experimental research: part IV-kinematic gait analysis to quantify peripheral nerve regeneration in the rat. International Review of Neurobiology, New York, v. 87, p. 127-139, 2009.

DeMEDINACELI, L.; FREED, W. J.; WYATT, R. J. An index of the functional condition of rat sciatic nerve based on measurements made from walking tracks. Experimental Neurology, New York, v. 77, n. 3, p. 634-643, 1982.

DOURADO, E. Reparación Microquirúrgica Del nervio facial de conejo. Estudio comparativo de la sutura epineural y el sistema adhesivo de fibrina. 2002. Tese (Doutorado em Odontologia) - Universidade de Barcelona, Barcelona.

EURIDES, D.; OLIVEIRA, B. J. N. A.; SOUZA, L. A.; SILVA, L. A. F.; DALECK, C. R.; FREITAS, P. M. C. Obtenção de células mononucleares da medula óssea pela punção do tubérculo umeral de coelhos. Ars Veterinária, Jaboticabal, v. 26, n. 2, p. 71-76, 2010.

EVANS, G. R. D. Challenges to nerve regeneration. Seminars in surgical oncology. New York, v. 19, n. 3, p. 312-318, 2000.

GUTMANN, E.; GUTMANN, L. Factors affecting recovery of sensory function after nerve lesions. Journal Neurology Psychiatry, London, v. 5, n. 3-4, p. 117-129, 1942.

HARCOURT-BROWN, F. Skin diseases. In: Textbook of rabbit medicine. Oxford: British $\overline{\text { Library, }}$ 2002. cap. 9, p. 224-248.

IM, G. I.; KIM, D. Y.; SHIN, J. H.; HYUN, C. W.; $\mathrm{CHO}, \mathrm{W} . \mathrm{H}$. Repair of cartilage defect in the rabbit with cultured mesenchymal stem cells from bone marrow. The Journal of Bone and Joint Surgery, Boston, v. 83, n. 2, p. 289-294, 2001.

NAVARRO, X.; UDINA, E. Methods and protocols in peripheral nerve regeneration experimental research: part iii -electrophysiological evaluation. Internacional Review of Neurobiology, New York, v. 87, p. 105-126, 2009.
NEIVA, P. Células que salvam vidas. 2005. Disponível em: <http://www.veja.abril.com.br/231105/p-118.html>. Acesso em: 10 jan. 2011.

OLIVEIRA, B. J. N. A. Enxerto osteocondral alógeno, associado á inoculação de células mononucleares da medula óssea e proteína morfogenética óssea no reparo do sulco troclear de coelhos. 2009. Dissertação (Mestrado em Ciências Veterinárias) - Faculdade de Medicina Veterinária. Universidade Federal de Uberlândia, Uberlândia.

SKARDA, R. T.; TRANQUILI, W. J. Local and regional anesthetic and analgesic techniques: cats. In: TRANQUILLI, W. J.; THURMON, J. C.; GRIMM, K. A. Lumb \& Jones veterinary anesthesia and analgesia. 4. ed. Philadelphia: Blacwell, 2007. cap. 21, p. 595-604.

SOUZA, L. A. Enxerto osteocondral alógeno, associado à inoculação de células mononucleares autólogas da medula óssea no reparo do sulco troclear de coelhos. 2009. Dissertação (Mestrado em Ciências Veterinárias) - Faculdade de Medicina Veterinária. Universidade Federal de Uberlândia, Uberlândia.

SUTER, S. E.; GOUTHRO, T. A.; MCSWEENEY, P. A.; NASH, R. A.; HASKINS, M. E.; FELSBURG, P. J.; HENTHORN, P. S. Isolation and characterization of pediatric canine bone marrow $\mathrm{CD} 34+$ cells. Veterinary Immunology and Immunopathology, Amsterdam, v. 101, n. 1-2, p. 31-47, 2004.

TRINDADE, A. B. Terapia celular na regeneração e recuperação funcional do defeito agudo do nervo femoral em coelhos Nova Zelândia (Oryctolagus cuniculus). 2009. Dissertação (Mestrado em Ciências Veterinárias) - Faculdade de Veterinária. Universidade Federal do Rio Grande do Sul, Porto Alegre.

YANAI, T.; ISHII, T.; CHANG, F.; OCHIAI, N. Repair of large full-thickness articular cartilage defects in the rabbit. The effects of joint distraction and autologous bone marrow- derived mesenchymal cell transplantation. The Journal of Bone and Joint Surgery, Boston, v. 87, n. 5, p. 721-729, 2005.

ZAGO, M. A.; COVAS, D. T. Pesquisas com células-tronco: aspectos científicos, éticos e sociais. In: SEMINÁRIO DO INSTITUTO FERNANDO HENRIQUE CARDOSO, 2004, São Paulo. Anais... São Paulo: Instituto Fernando Henrique Cardoso, 2004. p. 23. 
